\title{
PELAKSANAAN PROSEDUR EVALUASI PEMBELAJARAN BAHASA INDONESIA DI SMK PEKANBARU PADA MASA PANDEMI
}

\section{THE IMPLEMENTATION OF INDONESIAN LANGUAGE LEARNING EVALUATION PROCEDURES IN SMK PEKANBARU IN THE PANDEMIC PERIOD}

\author{
Muhammad Mukhlis', Heny Kusuma Widyaningrum²*, Akbar Al Masjid', \\ Kokom Komariah ${ }^{4}$, Sumarwati Sumarwati ${ }^{5}$ \\ Pendidikan Bahasa dan sastra Indonesia, Universitas Islam Riau, Indonesia ${ }^{1}$, \\ PGSD, Universitas PGRI Madiun, Indonesia ${ }^{2}$, \\ PGSD, Universitas Sarjanawiyata Tamansiswa, Indonesia ${ }^{3}$, \\ Pendidikan Bahasa Indonesia, Universitas Sebelas Maret, Indonesia ${ }^{4,5}$ \\ m.mukhlis@edu.uir.ac.id ${ }^{1}$, heny@unipma.ac.id ${ }^{2}$, almasjida@ustjogja.ac.id $^{3}$, \\ kokom.komariah09@student.uns.ac.id ${ }^{4}$, sumarwati@staff.uns.ac.id ${ }^{5}$ \\ *penulis korespondensi
}

\begin{tabular}{ll}
\hline Info Artikel & ABSTRAK \\
\hline Sejarah artikel: & Dalam proses pembelajaran tidak lepas dengan adanya evaluasi. Evaluasi \\
Diterima: & pembelajaran harus dilakukan secara sistematis dan berkesinambungan \\
20 Mei 2020 & guna mengetahui prosedur evaluasi pembelajaran yang baik. Penelitian ini \\
Direvisi: & bertujuan untuk mendeskripsikan pelaksanaan prosedur evaluasi \\
5 Juli 2021 & pembelajaran oleh guru Bahasa Indonesia di SMK di Pekanbaru tahun \\
Disetujui: & pelajaran 2020/2021. Penelitian ini bertujuan untuk mengumpulkan data \\
8 Juli 2021 & pelaksanaan evaluasi pembelajaran Bahasa Indonesia di SMK Pekanbaru. \\
& jenis penelitian yang digunakan ialah kualitatif. Data dikumpulkan melalui \\
Kata kunci: & angket. Data dianalisis dengan teknik deskriptif kualitatif. Pelaksanaan \\
pelaksanaan prosedur & evaluasi pembelajaran oleh guru Bahasa Indonesia di SMK Pekanbaru tahun \\
evaluasi pembelajaran, & pelajaran 2020/2021 dikategorikan cukup yaitu memeroleh angka (72,56\%). \\
guru Bahasa Indonesia,, & Kontribusi penelitian ini yaitu memberikan pengetahun kepada pembaca \\
masa pandemi & secara umum.
\end{tabular}

\begin{tabular}{ll}
\hline Article Info & ABSTRACT \\
\hline Article history: & In the learning process cannot be separated from the evaluation. Learning \\
Received: & evaluation must be carried out systematically and continuously in order to \\
20 May 2020 & find out a good learning evaluation procedure. This study aims to describe \\
Revised: & the implementation of learning evaluation procedures by Indonesian \\
5 July 2021 & language teachers at SMK at Pekanbaru in the 2020/2021 academic year. \\
Accepted: & This study aims to collect data on the implementation of Indonesian \\
8 July 2021 & language learning evaluation at SMK Pekanbaru. This study uses a \\
& qualitative research type. Data were collected through questionnaire. Data \\
Keyword: & were analyzed by qualitative descriptive technique. The implementation of \\
implementation of & the learning evaluation by Indonesian language teachers at SMK Pekanbaru \\
learning evaluation & in the 2020/2021 academic year is categorized as sufficient, namely getting \\
procedures, & a score $(72.56 \%)$ The contribution of this research is to provide knowledge \\
Indonesian & to readers in general.
\end{tabular}

Language teachers, the pandemic 


\section{PENDAHULUAN}

Evaluasi merupakan bagian yang tidak terpisahkan dalam proses pembelajaran. Dengan evaluasi seseorang pendidik akan mudah mengetahui sejauh mana tujuan pembelajaran tercapai. Evaluasi juga dapat menjadi pedoman bagi guru untuk melakukan umpan balik serta perbaikan untuk pembelajaran yang akan datang.

Hal tersebut juga dikemukakan oleh Atmazaki (2013) bahwa evaluasi pada dasarnya ialah proses mengumpulkan, menganalisis, dan meninterpretasikan informasi untuk melihat sejauh mana tujuan pembelajaran tercapai. Namun untuk melakukan evaluasi diperlukan tahapan yang terstandar sesuai kurikulum yang berlaku.

Arifin (2013) menyatakan bahwa ada delapan prosedur yang harus dilakukan dalam mengevaluasi pembelajaran. Kedelapan tersebut ialah perencanaa, pelaksanaa, monitoring, pelaksanaan, pengolahan data, pelaporan, dan penggunaan hasil evaluasi. Penerapan tahapan evaluasi tersebut dapat memberikan informasi yang baik terhadap potret ketercapaian tujuan pembelajaran dalam kurikulum tersebut.

Kurikulum adalah komponen yang penting dalam sistem pendidikan. Kurikulum merupakan komponen dalam pendidikan yang telah diselenggarakan satuan pendidikan dari pengelola, khususnya pendidik (guru dan kepala sekolah). Saat ini, Indonesia menerapkan Kurikulum 2013 yang berbasis kompetensi. Kurikulum berbasis kompetensi merupakan kurikulum dalam bentuk SKL (Standar Kompetensi Lulusan). Penilaian dalam hasil belajar dan kurikulum dari adanya pencapaian kompetensi (Kunandar, 2014).

Kurikulum 2013 memiliki empat komponen yang dimiliki, yakni komponen materi, tujuan, metode, dan evaluasi. Komponen evaluasi memberikan penilaian terhadap proses pembelajaran yang sudah dilakukan.

Evaluasi pembelajaran dilakukan oleh pihak sekolah dengan tujuan melihat keberhasilan dalam pembelajaran sehingga bisa diketahui faktor kekurangannya sehingga akan diambil langkah untuk memperbaiki.

. Harapan adanya evaluasi ini adalah mengetahui (Nazirun, Nurmalinda, \& Marhamah, 2015).

Penilaian merupakan bagian dari evaluasi. Evaluasi adalah proses untuk mendapatkan atau menentukan nilai, baik dari sisi belajar maupun pembelajaran dalam kegiatan penilaian. Penilaian merupakan proses melihat perbandingan keberhasilan siswa secara kuantutatif (Dimyati \& Mudjiono, 2013).

Proses kegiatan evaluasi dan pembelajaran tidak bisa dipisahkan. Keduanya penting dilakukan karena pembelajaran bertindak sebagai pendukung pengembangan dari potensi siswa, sedangkan evaluasi bertindak memberikan informasi keberhasilan pembelajaran. Tanpa evaluasi, maka akan sulit mengetahui kekurangan dari proses pembelajaran yang telah dilakukan.

Ada salah satu prinsip evaluasi pembelajaran, yaitu kebulatan. Prinsip kebulatan adalah prinsip untuk mengevaluasi secara keseluruhan dari siswa, baik dari segi pemahaman (kognitif), penghayatan (afektif), dan pengalaman (psikomotor) (Sudijono, 2011).

Hasil di salah satu SMKN Pekanbaru menunjukkan bahwa guru 
belum secara maksimal dalam melakukan penilaian pada mata pelajaran Bahasa Indonesia di nilai penilaian. Guru hanya melakukan pengamatan saja secara langsung, tanpa instrumen. Guru cenderung menilai secara kognitif. Berdasarkan permasalahan tersebut, peneliti tertarik melaksanakan penelitian evaluasi pembelajaran di SMKN Pekanbaru untuk mengetahui prosedur pembelajaran mata pelajaran Bahasa Indonesia.

Kegiatan evaluasi, pengukuran, dan penilaian merupakan program yang dilakukan secara simultan dan sistematis. Maksudnya ketiga program tersebut tidak bisa dipisahkan satu sama lain di dalam proses belajar mengajar. Pelaksanaannya harus dilaksanakan secara sistematis berkelanjutan. Dalam hal ini, ada dua istilah yang hampir sama namun sedikit berbeda maksud tujuannya, yakni istilah penilaian dan pengukuran.

Pengukuran (measurement) mengarah pada suatu tindakan atau proses untuk mengetahui kuantitas sesuatu. Sedangkan penilaian atau evaluasi (assessment) mengarah pada penentuan kualitas atau untuk perbaikan kualitas dari sesuatu.

Tujuan umum assessment dalam pembelajaran untuk mengetahui efektivitas dan efisiensi suatu pembelajaran, mulai dari perencanaan pembelajaran, pelaksanaan, dan hasil pembelajarannya. Adapun tujuan khusus dari assessment pembelajaran dapat disesuaikan dengan jenis evaluasi yang akan dilakukan, seperti evaluasi pembelajaran, evaluasi program kebijakan pembelajaran, evaluasi perencanaan dan proses, monitoring dan evaluasi, evaluasi dampak, maupun evaluasi efisiensi-ekonomis (Arifin, 2016).
Evaluasi pembelajaran memiliki beberapa fungsi. Menurut Jihad \& Haris (2013) fungsi dari evaluasi pembelajaran adalah formatif, sumatif, diagnostik, selektif, motivasi. Evaluasi formatif adalah jenis evaluasi yang dilaksanakan di saat program pembelajaran berlangsung, sebagai umpan balik antara peserta didik dengan pendidik. Tes sumatif adalah suatu tes yang biasanya dilakukan di akhir proses/program pembelajaran, yang digunkan untuk mengukur penguasaan pengetahuan dan keterampilan yang sudah dipelajari secara keseluruhan. Fungsi diagnostik, yaitu fungsi evaluasi yang dipakai untuk mengungkapkan mengidentifikasi kesulitan dan kekuatan peserta didik. Fungsi selektif, adalah fungsi evaluasi sebagai alat untuk menyeleksi masukan (input) SDM yang sesuai kriteria yang dibutuhkan suatu instansi penyeleksi. Yang terakhir fungsi motivasi, di sini evaluasi dilakukan guna meningkatkan semangat dan minat serta kompetensi peserta didik.

Keberhasilan evaluasi pmbelajaran juga dipengaruhi oleh teknis evaluator dalam melaksanakan langkah-langkah evaluasi. Langkahlangkah evaluasi yang dimaksud adalah prosedur pokok yang harus dilakasanakan dalam aktivitas program evaluasi. Adapun langkah-langkah yang perlu dilaksanakan evaluator diantaramya adanya perencanaan evaluasi, pelaksanaan evaluasi dan monitoring, pengolahan data dan analisis, pelaporan, serta pemanfaatannya (Arifin, 2016).

Perencanaan evaluasi, adalah setiap kegiatan pendidikan selalu dimulai dengan perencanaan. Suatu proses atau hasil kegaiatan yang baik adalah yang sesuai dengan yyang sudah 
direncanakan.

Implikasinya, perencanaan evaluasi harus disetting secara spesifik, terurai, serta komprehensif sehingga perencanaan (planning) dapat bermakna dalam menentukan tahapan berikutnya. Perencanaan evaluasi yang dipersiapkan secara matang oleh seorang evaluator terlebih dahulu dapat menetapkan tujuan tingkah laku (behavioral Objektive) atau tolok ukur yang ingin dicapai. kemudian evaluator akan mempersiapkan pengumpulan data serta informasi yang diperlukan untuk dapat mengefisiensikan waktu.

$$
\text { Pelaksanaan }
$$
evaluasi dilakakukan saat memonitoring proses pembelajaran apakah sudah sesuai dengan perencanaan dan ttarget pembelajaran yang ingin dicapai. Hasil Penerapan evaluasi berkaitan dengan jenis evaluasi yang diterapkan. Jenis evaluasi akan menentukan bentuk instrument, prosedur, metode yang digunakan, sumber data, waktu pelaksanaan, serta faktor-faktor lainnya. Untuk melaksanaan evaluasi hasil belajar, seorang guru sebagai evaluator dapat menggunakan alat berupa tes tertulis, tes lisan, dan tes kinerja atau dapat juga dengan non-tes misalnya menggunakan angket, pedoman wawancara, skala sikap, pedoman observasi, studi dokumentasi, dan sebagainya) (Arifin, 2014).

Pemantauan pelaksanaan evaluasi perlu dilakukan guna mengevaluasi pelaksanaan pembelajaran telah berjalan sesuai dengan perencanaan. Tujuannya yaitu untuk menanggulangi hal-hal yang yang tidak diinginkan dan mengoptimalkan efisiensi pelaksanaan evaluasi. Monev (monitoring evaluasi) memiliki dua fungsi utama, yaitu untuk melihat kesesuaian pelaksanaan evaluasi dengan rencana program, dan untuk melihat perihal sesuatu yang terjadi selama pelaksanaan program. Apabila pelaksanaan evaluasi terjadi hal-hal yang melenceng dari rencana program, evaluator harus mengidentifikasi dan menganalisis faktor-faktor penyebabnya yang selanjutnya dilakukan perbaikan dan penerapan solusinya.

Pengolahan data dilakukan jika data primer dan sekunder sudah terkumpul. Pemrosesan/pengolahan data merupakan aktivitas mengubah wujud data yang sudah terkumpul menjadi sebuah sajian data yang bermakna dan terbaca. Data hasil evaluasi tersebut, ada yang berjenis kualitatif, ada pula yang berjenis kuantitatif. Data selanutnya dianalisis secara kualitatif yakni menggunakan huruf atau kata-kata, sedangkan data kuantitatif dianalisis dengan statistik. atau angka-angka.

Semua hasil evaluasi sebaiknya diinformasikan kepada pihak yang berkepentingan. Hal tersebut bisa disampaikan kepada orangtua/wali, steakholder, kepala sekolah, serta peserta didik. kegiatan ini sebagai wujud akuntabilitas pelaksanaan pembelajaran. Hal tersebut mempunyai tujuan agar semua pihak dapat mengetahui pencapaian proses-proses pembelajaran dan kemajuan peserta didik. Pelaporan perkembangan belajar peserta didik sebagai sarana komunikasi antara sekolah, peserta didik, dan orangtua dalam upaya mengetahui perkembangan peserta didik dan ikut serta memberikan support agar kegiatan belajarnya dapat terpantau dan meningkat.

Langkah akhir dari prosedur pelaksanaan evaluasi adalah memanfaatkan hasilnya. Salah satu pemanfaat hasil evaluasi ialah memberikan umpan balik. Laporan 
belajar peserta didik memiliki maksud untuk memberikan umpan balik pada semua pihak yang terlibat dan tanggung jawab terhadap pembelajaran. Pihak tersebut di antaranya kepala sekolah, orang tua, guru, steak holder serta peserta didik itu sendiri.

Studi pendahuluan menjelaskan bahwa waktu pelaksanaan evaluasi bisa dilaksanakan secara lebih flesibel artinya bisa dilakukan kapan saja asalkan sebelumnya materi sudah disampaikan oleh guru (Batubara, 2016). Tujuan utama evaluasi, baik umtuk pendidik maupun peserta didik harus dipersiapkan sebelum evaluasi tersebut dilaksanakan agar target yang diinginkan tercapai atau bahkah dapat melampaui target KKM (Kriteria Ketuntasan Minimal). Walaupun evaluasi pembelajaran pada umumnya dilaksanakan di akhir pembelajaran, namun seyogyannya evaluasi dirancang dan disiapkan sebelum pembelajaran dilakukan sehingga tujuan program dari evaluasi ini dapat terarah, namun tetap memperhatikan perkembangan konteks pembelajaran saat nanti berlangsung (Aulia, dkk, 2020).

Penelitian Iwanto (2014) mejelaskan bahwa evaluasi yang baik hendaknya berpatokkan pada tujuan yang telah ditetapkan dan berdasarkan perencanaan yang disusun serta berdasarkan ketersediaan prasarana dan sarana yang mendukung pembelajaran. Betapapun baiknya evaluasi jika tidak sesuai dengan tujuan yang telah ditetapkan, maka itu non-sense. Proses evaluasi harus tepat sesuai tujuan yang ingin dicapai. (Sukardi, 2011).

\section{METODE}

Penelitian yang penulis lakukan ini menggunakan metode deskriptif. Subana (2005) mengatakan bahwa penelitian deskriptif merupakan penelitian yang tujuannya untuk menyajikan secara apa adanya tentang fakta, keadaan fenomena yang sedang terjadi. Penelitian ini dimaksudkan untuk mengumpulkan data pelaksanaan evaluasi pembelajaran bahasa Indonesia di SMK Pekanbaru tahun pelajaran 2020/2021.

Data dikumpulkan dengan menggunakan angket. Widoyoko, 2016) mengatakan bahwa teknik dengan menggunakan angket dilakukan dengan memberikan seperangkat pertanyaan tertulis kepada responden sesuai dengan permintaan penggunanya. Dalam penelitian ini kuesioner (angket) diberikan kepada 6 orang guru bahasa Indonesia di dua SMK Pekanbaru tahun pelajaran 2020/2021 guna memperoleh informasi tentang pelaksanaan evaluasi pembelajaran bahasa Indonesia. Teknik ini sebagai data primer dalam penelitian ini.

Adapun analisis data dalam penelitian ini menggunakan analisis deskriptif kualitatif. Hal ini digunakan untuk menganalisis data yang diperoleh dari hasil angket. Dalam penelitian kuantitatif, dilakukan proses penyederhaan data dalam bentuk tabel, sehingga lebih mudah untuk dianalisi serta diinterpretasikan. Data yang terkumpul kemudian dianalisis untuk mendapatkan gambaran keseluruhan tentang objek penelitian, maka selanjutnya dilakukan pengolahan data.

\section{HASIL DAN PEMBAHASAN}

Hasil dan pembahasan dibahas satu persatu mengenai pelaksanaan prosedur evaluasi pembelajaran. Hasil dan pembahasan dilakukan berdasarkan data yang telah diperoleh memalui angket. Lebih jelas akan dibahas berikut ini. 


\section{Perencanaan Evaluasi Pembelajaran Oleh Guru}

Bagian yang paling penting dalam proses evaluasi adalah perencanaan evaluasi. Sebelum diimplementasikan hendaknya memiliki perencanaan evaluasi yang baik. Hal tersebut akan memperlancar sesuai dengan tujuan yang ingin dicapai. Seperti yang disampaikan oleh Harahap, dkk (2018) dalam perencanaan evaluasi pembelajaran harus merumuskan tujuan karena akan memperbaiki sistem dan metode dalam pembelajaran. Selanjutnya supaya berjalan dengan lancar terdapat beberapa hal yang harus dipersiapkan dalam perencanaan evaluasi pembelajaran. Seperti yang disampaikan Riadi (2017) perencanaan evaluasi pembelajaran yang harus dipersiapkan oleh guru diantaranya, merumuskan tujuan, menetapkan aspek-aspek yang akan dievaluasi, memilih dan menentukan teknik, menyusun alat-alat pengukur, menentukan tolok ukur, norma atau kriteria, serta menentukan frekuensi kegiatan evaluasi.

Pertanyaan tentang aspek perencanaan evaluasi pembelajaran oleh Guru bahasa Indonesia di SMK Pekanbaru Tahun Ajaran 2020/2021 terdiri dari 6 pertanyaan. Berdasarkan hasil analisis data penelitian tentang perencanaan evaluasi pembelajaran oleh Guru bahasa Indonesia di SMK Pekanbaru Tahun Ajaran 2020/2021 diperoleh persentase yang menjawab selalu 42,67\%, menjawab sering $41,67 \%$, mejawab kadang-kadang $16,66 \%$ dan yang menjawab tidak dpernah $0 \%$. Lebih rinci data tersebut tersaji dalam tabel berikut ini.
Tabel 1. Persentase Guru dalam Perencanaan Evaluasi Pembelajaran Bahasa Indonesia di SMK Pekanbaru Tahun Ajaran 2020/2021

\begin{tabular}{|l|l|c|c|}
\hline No & \multicolumn{1}{|c|}{ Kriteria } & f & $\begin{array}{c}\text { Persen- } \\
\text { tase }\end{array}$ \\
\hline 1. & Selalu & 15 & $41,67 \%$ \\
\hline 2. & Sering & 15 & $41,67 \%$ \\
\hline 3. & Kadang-kadang & 6 & $16,66 \%$ \\
\hline 4. & Tidak pernah & 0 & $0 \%$ \\
\hline \multicolumn{2}{|c|}{ Jumlah } & 36 & $100 \%$ \\
\hline
\end{tabular}

Selanjutnya, jika dihitung berdasarkan total Skor yang diperoleh dri angket, maka rata-rata persentase guru dalam merencanakan evaluasi pembelajaran $81,3 \%$. Berdasarkan kriteria penghitungan persentasi skala 4, maka untuk diperoleh kriteria baik sekali. Dengan demikian, prosedur pertama tentang guru harus membuat perencanaan evaluasi telah dilaksanakan dengan baik sekali. Artinya dalam melakukan evaluasi aspek perencanaan sangatlah penting. Perencanaan yang matang tentunya akan berdampak dalam keberhasilan dalam melaksanakan evaluasi.

\section{Pelaksanaan Evaluasi Pembelajaran oleh Guru}

Guru harus mempunyai kompetensi dalam melakukan evaluasi pembelajaran. Pelaksanaan evaluasi pembelajaran dilakukan oleh guru berdasarkan langkah yang ditetapkan. Riadi (2017) menyatakan bahwa pelaksanaan evaluasi pembelajaran harus berdasarkan langkah-langkah yang telah ditetapkan, langkah-langkah tersebut diantaranya melakukan perencanaan, membuat soal untuk tes, mengolah hasil tes lalu mennganalisnya, serta melakukan interpretasi terhadap hasil evaluasi tersebut. Sedangkan hermawan (2018) mengatakan bahwa dalam pembelajaran, evaluasi itu sangat 
penting dan harus mengacu pada prinsip-prinsip evaluasi supaya mendapatkan informasi yang benar tentang hasil belajar siswa..

Pernyataan tentang aspek pelaksanaan evaluasi pembelajaran oleh Guru Bahasa Indonesia di SMK Pekanbaru tahun pelajaran 2020/2021 terdiri dari satu pertanyaan. Berdasarkan hasil analisis data penelitian tentang pelaksanaan evaluasi pembelajaran oleh Guru bahasa Indonesia di SMK Pekanbaru tahun pelajaran 2020/2021 diperoleh persentase yang menjawab selalu $16,67 \%$, menjawab sering $50 \%$, mejawab kadang-kadang 33,33\% dan yang menjawab tidak dpernah $0 \%$. Lebih rinci data tersebut tersaji dalam tabel berikut ini.

Tabel 2. Persentase Guru dalam Pelaksanaan Evaluasi Pembelajaran Bahasa Indonesia di SMK Pekanbaru Tahun Ajaran 2020/2021

\begin{tabular}{|l|l|c|c|}
\hline No & \multicolumn{1}{|l|}{ Kriteria } & F & $\begin{array}{l}\text { Per- } \\
\text { sentase }\end{array}$ \\
\hline 1. & Selalu & 1 & $16,67 \%$ \\
\hline 2. & Sering & 3 & $50,00 \%$ \\
\hline 3. & Kadang-kadang & 2 & $33,33 \%$ \\
\hline 4. & Tidak pernah & 0 & $0 \%$ \\
\hline \multicolumn{2}{|c|}{ Jumlah } & 6 & $100 \%$ \\
\hline
\end{tabular}

Selanjutnya, jika dihitung berdasarkan total Skor yang diperoleh dari angket, maka kesesuaian evaluasi yang dilakukan guru dengan rencana diperoleh rata-rata $70,8 \%$. Berdasarkan kriteria penghitungan persentasi skala 4, maka pelaksanan evaluasi termasuk dalam kriteria cukup. Dengan demikian, prosedur kedua tentang guru harus melaksanakan evaluasi berdasarkan perencanaan yang telah dibuat perlu untuk ditingkatkan kembali. Hal tersebut terdapat beberapa faktor diantaranya, kurangnya pemahaman guru dalam melaksanakan apa yang dirancang, ketidaksesuaian rancangan dengan kondisi dalam melaksanakan evaluasi, dan waktu yang tidak cukup untuk melaksanakan semua yang telah dirancang.

\section{Monitoring Pelaksanaan Evaluasi Pembelajaran Oleh Guru}

Monitoring dalam pelaksanaan evalusai dapat berjalan dengan baik apabila dirancang terlebih dahulu. Wijaya (2018) mengatakan bahwa untuk menjalankan sebuah proses monitoring dibutuhkan perencanaan yang matang. Adapun Muhanifah (2017) mengatakan bahwa dalam monitoring harus berdasarkan pada prinsisp-prinsip yaitu tanggung jawab dan kewenangan, periodik, demokratis, terbuka, dan berkelanjutan. Hal ini dilakukan agar pelaksanaan evaluasi pembelajaran tetap berjalan sesuai dengan tujuan yang hendak dicapai.

Monitoring dalam pelaksanaan evaluasi sangat penting. Berdasarkan data, monitoring pelaksanaan evaluasi pembelajaran oleh Guru Bahasa Indonesia di SMK Pekanbaru Tahun Ajaran 2020/2021 diperoleh persentase yang menjawab selalu $0 \%$, menjawab sering $16,67 \%$, mejawab kadangkadang $50 \%$ dan yang menjawab tidak pernah $33,33 \%$. Lebih rinci data tersebut tersaji dalam tabel berikut ini.

Tabel 3. Persentase Guru dalam Monitoring Pelaksanaan Evaluasi Pembelajaran Bahasa Indonesia di SMK Pekanbaru Tahun Ajaran 2020/2021

\begin{tabular}{|c|c|c|c|}
\hline No & Kriteria & $\mathbf{F}$ & $\begin{array}{c}\text { Persen- } \\
\text { tase }\end{array}$ \\
\hline 1. & Selalu & 0 & $0 \%$ \\
\hline 2. & Sering & 1 & $16,67 \%$ \\
\hline 3. & Kadang-kadang & 3 & $50,00 \%$ \\
\hline 4. & Tidak pernah & 2 & $33,33 \%$ \\
\hline \multicolumn{2}{|r|}{ Jumlah } & 6 & $100 \%$ \\
\hline
\end{tabular}


Selanjutnya, jika dihitung berdasarkan total skor yang diperoleh dari angket, rata-rata persentase guru melakukan monitoring dalam pelaksanaan evaluasi pembelajaran 45,8\%. Berdasarkan kriteria penghitungan persentasi skala 4, monitoring dalam pelaksanan evaluasi termasuk dalam kriteria kurang. Dengan demikian, prosedur ketiga tentang guru harus melakukan monitoring terhadap pelaksanaan evaluasi sangat perlu untuk ditingkatkan kembali.

\section{Melakukan Pengolahan Data Evaluasi Pembelajaran}

Pengolahan data hasil evaluasi merupakan prosedur yang menyajikan data agar lebih bermakna. Pada prosedur inilah dapat diketahui prestasi setiap siswa dan ketercapaian tujuan pembelajaran. Berdasarkan data bahwa guru melakukan pengolahan data hasil evaluasi pembelajaran memperoleh persentase sebagai berikut. Guru yang menjawab selalu $66,67 \%$, menjawab sering 33,33\%, mejawab kadangkadang $0 \%$ dan yang menjawab tidak pernah $0 \%$. Lebih rinci data tersebut tersaji dalam tabel berikut ini.

Tabel 4.Persentase Guru Melakukan

Pengolahan Data Evaluasi

Pembelajaran Bahasa Indonesia di

SMK Pekanbaru Tahun Ajaran 2020/2021

\begin{tabular}{|l|l|c|c|}
\hline No & \multicolumn{1}{|c|}{ Kriteria } & F & $\begin{array}{l}\text { Persenta- } \\
\text { se }\end{array}$ \\
\hline 1. & Selalu & 8 & $66,67 \%$ \\
\hline 2. & Sering & 4 & $33,33 \%$ \\
\hline 3. & Kadang-kadang & 0 & $0 \%$ \\
\hline 4. & Tidak pernah & 0 & $0 \%$ \\
\hline \multicolumn{2}{|l|}{ Jumlah } & 12 & $100 \%$ \\
\hline
\end{tabular}

Selanjutnya, jika dihitung berdasarkan total Skor yang diperoleh melalui angket, rata-rata persentase guru melakukan pengolahan data pada setiap pelaksanaan evaluasi pembelajaran ialah $91,7 \%$. Berdasarkan kriteria penghitungan persentasi skala 4, guru melakukan prosedur pengolahan data pada setiap pelaksanaan evaluasi pembelajaran termasuk dalam kriteria baik sekali. Dengan demikian, prosedur keempat tentang guru harus melakukan pengolahan data evaluasi sudah dilaksanakan dengan baik sekali. Artinya, dengan kriteria ini diharapkan setiap evaluasi yang dilakukan akan memberikan informasi yang jelas tentang prestasi siswa.

Dari pengolahan data di atas dapat diketahui hasil penafsiran pengolahan data sehingga sebagai peneliti dapat memberikan statement atas interpretasi atas dasar pengolahan data yang dilakukan. Hal ini sejalan dengan apa yang disampaikan oleh Suardipa \& Primayana (2020) bahwa dalam mengolah data itu arinya kita mau memberikan nilai kepada siswa. Sependapat dengan pernyataan tersebut Makbul (2021) mengatakan bahwa interpretasi bertujuan untuk memberikan informasi mengenai hasil pengolahan data. Interpretasi yang dilakukan terhadap hasil evaluasi harus berdasarkan kriteria yang ditetapkan.

\section{Melakukan Pelaporan Evaluasi Pembelajaran}

Pelaporan terhadap hasil evaluasi yang dilakukan dimaksud untuk mendapatkan umpan balik dari beberapa pihak yang berkepentingan seperti siswa, wali murid, sekolah, dll. Berdasarkan data bahwa guru melakukan pengolahan data hasil evaluasi pembelajaran memperoleh persentase sebagai berikut. Guru yang menjawab selalu $16,67 \%$, menjawab sering $33,33 \%$, mejawab kadang- 
kadang $50 \%$ dan yang menjawab tidak pernah $0 \%$. Lebih rinci data tersebut tersaji dalam tabel berikut ini.

Tabel 5. Persentase Guru Melakukan

Pengolahan data Evaluasi

Pembelajaran Bahasa Indonesia di

SMK Pekanbaru Tahun Pelajaran $2020 / 2021$

\begin{tabular}{|l|l|c|c|}
\hline No & \multicolumn{1}{|c|}{ Kriteria } & f & $\begin{array}{c}\text { Persen- } \\
\text { tase }\end{array}$ \\
\hline 1. & Selalu & 8 & $16,67 \%$ \\
\hline 2. & Sering & 4 & $33,33 \%$ \\
\hline 3. & $\begin{array}{l}\text { Kadang- } \\
\text { kadang }\end{array}$ & 12 & $50 \%$ \\
\hline 4. & Tidak pernah & 0 & $0 \%$ \\
\hline \multicolumn{2}{|r|}{ Jumlah } & 24 & $100 \%$ \\
\hline
\end{tabular}

Selanjutnya, jika dihitung berdasarkan total skor yang diperoleh melalui angket, rata-rata persentase guru melaporkan hasil evaluasi kepada pihak yang berkepentingan ialah $66,7 \%$. Berdasarkan kriteria penghitungan persentasi skala 4, prosedur pelaporan hasil evaluasi termasuk dalam kriteria cukup. Dengan demikian, prosedur kelima tentang guru harus melaporkan hasil evaluasi kepada berbagai pihak yang berkepentingan perlu ditingkatkan lagi. Hal ini tentu menjadi perhatian bagi seorang evaluator bahwa menginformasikan hasil evaluasi dapat menjadi motivasi bagi siswa dan lainnya untuk selalu meningkatkan mutu belajar ataupun mutu pendidikan pada umumnya. Selain itu, dengan menginformasikan hasil tersebut akan mendapatkan umpan balik bagi guru terhadap prestasi yang telah dicapai oleh siswa.

Laporan hasil evaluasi penting untuk disampaikan pada berbagai pihak terkait baik guru, sekolah, orangtua dan siswa itu sendiri. Hal ini sesuai apa yang diuatakan oleh Reni, (2019) bahwa laporan hasil evaluasi pembelajaran dapat menjadi umpan balik bagi berbagai pihak, baik guru, sekolah, orang tua dan siswa. Hal ini bertujuan agar adanya umpan balik terhadap proses dan hasil yang dicapai peserta siswa. Selain itu, orang tua dan pihak terkait dapat mengambil sikap dan langkah-langkah sebagai tindak lanjut dari laporan tersebut. Penyampaian hasil evaluasi pembelajaran ini perlu dilakukan dengan kerjasama dengan berbagai pihak terutama orangtua dengan melakukan komunikasi efektif sberkaitan dengan kegiatan pembelajaran (Maryani, 2020).

\section{Penggunaan Hasil Evaluasi Pembelajaran}

Penggunaan terhadap hasil evaluasi yang dilakukan perlu dipertimbangkan. Hal ini karena evaluasi dilakukan untuk tujuan tertentu. Tujuan tersebut bisa berupa untuk keperluan seleksi, promosi, laporan pertanggungjawaban, dan diagnosis. Berdasarkan data bahwa guru telah menggunakan hasil evaluasi pembelajaran untuk tujuan dan keperluan tertentu memperoleh persentase sebagai berikut. Guru yang menjawab selalu 41,67\%, menjawab sering $33,33 \%$, mejawab kadangkadang 25,\% dan yang menjawab tidak pernah $0 \%$. Lebih rinci data tersebut tersaji dalam tabel berikut ini.

Tabel 6. Persentase Guru

Menggunakan Hasil Evaluasi

Pembelajaran Bahasa Indonesia

\begin{tabular}{|l|l|c|c|}
\hline No & \multicolumn{1}{|c|}{ Kriteria } & f & Persentase \\
\hline 1. & Selalu & 5 & $16,67 \%$ \\
\hline 2. & Sering & 4 & $33,33 \%$ \\
\hline 3. & $\begin{array}{l}\text { Kadang- } \\
\text { kadang }\end{array}$ & 3 & $50 \%$ \\
\hline 4. & Tidak pernah & 0 & $0 \%$ \\
\hline \multicolumn{2}{|c|}{ Jumlah } & 12 & $100 \%$ \\
\hline
\end{tabular}


Selanjutnya, jika dihitung berdasarkan total skor yang diperoleh melalui angket, rata-rata persentase guru selalu menggunkan hasil evaluasi untuk tujuan dan keperluan tertentu ialah 79,2\%. Berdasarkan kriteria penghitungan persentasi skala 4, prosedur penggunaan terhadap hasil evaluasi termasuk dalam kriteria baik. Dengan demikian, prosedur keenam tentang guru harus menggunakan hasil evaluasi yang dilakukannya untuk tujuan dan keperluan tertentu sudah diterapkan degan baik.

Evaluasi menjadi bagian dari kompetensi pedagogi dan bagian dari kinerja guru (Pauji et al., 2016). Baik evaluasi proses maupun hasil pemebalajarn hasur dilakukan secara berkesinambungan supaya dapat memperbaiki kualitas pembelajaran secara signifikan. Sependapat dengan Pauji, dkk (2016) penggunaan hasil evaluasi ini menurutnya dapat bermanfaat untuk siswa baik dalam mempromosikan siswa, mendiagnosa kelemahan dan kekurangan siswa, untuk mengelompokkan siswa, untuk pemberian umpan balik, dapat pula untuk laporan kepada orang tua, untuk pertimbangan dalam perencanaan pembelajaran, serta untuk pertimbangan perlu tidaknya remedial. Senada dengan pendapat Pauji, dkk., Elis Ratna Wulan \& Rusdian (2015) menjelaskan bahwa hasil evaluasi pembelajaran dapat digunakan dalam ruang lingkup terbatas dan luas. Pada lingkup terbatas dilakukan untuk mengetahui tingkat keberhasilan siswa. Selanjutnya, pada lingkup luas yang dilakukan untuk mengetahui kekurangan dalam mencapai tujuan pembelajaran.

\section{PENUTUP}

Berdasarkan persentase pada masing-masing aspek keterlaksanaan proseudr evaluasi pembelajaran oleh guru Bahasa Indonesia di SMK di Pekanbaru tahun pelajaran 2020/2021, dapat diambil kesimpulan bahwa pelaksanaan evaluasi pembelajaran oleh guru bahasa Indonesia di SMK Pekanbaru tahun pelajaran 2020/2021 dikategorikan cukup yaitu memeroleh angka (72,56\%). Untuk lebih jelasnya, data tersebut dapat dijabarkan sebagai berikut. Aspek perencanaan evaluasi persentase $81,3 \%$, aspek pelaksanaan evaluasi $70,8 \%$, aspek monitoring pelaksanaan evaluasi sebesar 45,8\%, aspek pengolahan data hasil evauasi $91,7 \%$, aspek pelaporan data hasil evaluasi $66,7 \%$, dan aspek penggunaan data hasil evaluasi 79,2\%. Rata-rata rekapitulasi pelaksanaan prosedur evaluasi sebesar $72,56 \%$.

Berdasarkan data di atas, dapat disimpulkan bahwa pelaksanaan evaluasi pembelajaran oleh guru Bahasa Indonesia di SMK Pekanbaru tahun pelajaran 2020/2021 beberapa ketentuan sudah dilaksanakan sesuai dengan prosedur pelaksanaan evaluasi pembelajaran. Namun, untuk poin tertentu menjadi perhatian bagi guru. Hal tersebut tentunya evaluasi yang dilaksanakan tidak maksimal. Oleh karena itu, dengan adanya kelemahan tersebut, ada beberapa saran, yaitu meningkatkan kemampuan guru melalui pelatihan-pelatihan, adanya kerjasama antar guru dan orang tua dalam pelaksanaan evaluasi pembelajaran.

\section{DAFTAR PUSTAKA}

Arifin, Z. (2013). Evaluasi Pembelajaran (Prinsip, Teknik, dan Prosedur). Remaja Rosdakarya. 
Arifin, Z. (2016). Evaluasi Pembelajaran. Remaja Rosdakarya.

Arikunto, S. (2006). Prosedur Penelitian (Suatu Pendekatan Praktik). Rineka Cipta.

Atmazaki. (2013). Penilaian Alternatif dalam Pembelajaran Bahasa Indonesia. Padang: UNP Press.

Aulia, R. N., Rahmawati, R., \& Permana, D. (2020). Peranan Penting Evaluasi Pembelajaran Bahasa di Sekolah Dasar. Jurnal BELAINDIKA (Pembelajaran Dan Inovasi Pendidikan), 2(1), 1-9.

Batubara, H. H. (2016). Penggunaan google form sebagai alat penilaian kinerja dosen di Prodi PGMI Uniska Muhammad Arsyad Al Banjari. Al-Bidayah: Jurnal Pendidikan Dasar Islam, 8(1).

Dimyati, \& Mudjiono. (2013). Belajar dan Pembelajaran. Rineka Cipta.

Elis Ratna Wulan, E., \& Rusdiana, A. (2015). Evaluasi pembelajaran. Pustaka Setia.

Harahap, Hayat, Mardianto, Wahyudin Nur Nasution. (2018). Perencanaan,Pengembangan dan Pelaksanaan Evaluasi Pembelajaran PAI di SDN 064988 Medan Johor. Edu Riligia:Vol. 2 No.3 JuliSeptember

Hermawan, Adhi Oktavian. (2018). Pelaksanaan Evaluasi dalam Pembelajaran Pendidikan Jasmani Olahraga dan
Kesehatan di SekolahDasar Negeri Se-Kecamatan Pedan Kabupaten Klaten. Skripsi.Universitas Negeri Yogyakarta.

Jihad, A., \& Haris, A. (2013). Evaluasi Pembelajaran. Multi Pressindo.

Kunandar. (2014). Penilaian Autentik (Penilaian hasil belajar peserta didik berdasarkan kurikulum 2013) suatu pendekatan praktik. Rajagrafindo persada.

Makbul, M. (2021). Pengembangan Evaluasi Pembelajaran. Seminar Program Pascasarjana Universitas Islam Negeri Alaudin Makassar. https://osf.io/wvhtz

Maryani, K. (2020). Penilaian dan Pelaporan Perkembangan Anak Saat Pembelajaran di Rumah di Masa Pendemi Covid-19. Murhum: Jurnal Pendidikan Anak Usia Dini, 41-52.

Miswanto, M. (2014). Evaluasi Pendidikan Agama Islam Berbasis

Karakter. Madaniyah, 4(2), 151-164.

Muhainifah, Isni. (2017). Monitoring dan Evaluasi Pelaksanaan Pembelajaran pada Kinerja Guru Penjasorkes Melalui Supervisi.Indonesian Journal on Education and Research Volume 2 No 4-2017.

Nazirun, Nurmalinda, \& Marhamah. (2015). Kurikulum dan Pembelajaran. Forum Kerakyatan.

Pauji, R., Trisna, B. N., \& Atsnan, M. 
F. (2016). Pemanfaatan hasil evaluasi pembelajaran matematika SMA di kota Banjarmasin. Math Didactic: Jurnal Pendidikan Matematika, 2(3), 164-170.

Reni, \& A. B. (2019). Prosedur Pengelolaan dan Pelaporan Hasil Evaluasi Pembelajaran. Seminar Nasional Taman Siswa Bima, 1(1), 317-320.

Riadi, Akhmad. (2017). Kompetensi Guru dalam Pelaksanaan Evaluasi Pembelajaran. Ittihad Jurnal Kopertais Wilayah XI Kalimantan Volume 15 No. 28 Oktober 2017.

Suardipa, I. P., \& Primayana, K. H. (2020). Peran desain evaluasi pembelajaran untuk meningkatkan kualitas pembelajaran. Widyacarya:
Jurnal Pendidikan, Agama Dan Budaya, 4(2), 88-100.

Subana, S. (2005). Dasar-Dasar Penelitian Ilmiah. Pustaka Setia.

Sudijono, A. (2011). Pengantar Evaluasi Pendidikan. Rajawali Pers.

Sukardi. (2011). Evaluasi Pendidikan Prinsip dan Operasionalnya. Jakarta: Bumi Aksara.

Widoyoko, E. P. (2016). Teknik Penyusunan Instrumen Penelitian. Pustaka Pelajar.

Wijaya, C A. (2018). Sistem Monitoring dan Evaluasi Pengelolaan Program Studi di Institusi Pendidikan Tinggi. Indonesian Journal of Information Systems (IJIS)Vol. 1, No. 1, Agustus 2018. 